\title{
THE WORK OF MAX VON PETTENKOFER.
}

The death of Professor von Pettenkofer, which was briefly alluded to in the last issue of the Journal of Hygiene, has removed one who was everywhere acknowledged as a great leader among the workers in our science, and as the pioneer who has been mainly instrumental in bringing about the recognition of Hygiene, particularly on its experimental side, as a separate subject of investigation and university instruction.

Pettenkofer was born in 1818 near Neuburg in Bavaria. His parents were very poor, but when he was nine years old an uncle, who was druggist to the Court at Munich, undertook to provide for his education. After finishing his course at the "Gymnasium" he studied for two years at the University of Munich, and when 21 years old was apprenticed as a druggist. Not content with this work he suddenly gave it up, and became for a short time an actor, but after a few months returned to Munich and worked for a degree in medicine, which he obtained in 1843 .

$\mathrm{He}$ had already become interested in scientific investigations, and now determined not to practise, but to obtain if possible a university pasition in which he could devote himself to science. He went accordingly to work in Scherer's laboratory at Würzburg, and later to the still more famous laboratory of Liebig at Giessen. The subject to which he specially devoted himself during the year thus spent, was Physiological Chemistry; and he very quickly made for himself a name by his discovery of creatinin in urine, and of the familiar test for bile acids which is so well known as "Pettenkofer's reaction."

On his return to Munich the University authorities recommended to the Government that a Professorship of Physiological Chemistry should be founded and conferred on Pettenkofer. This recommendation was however set aside, and he had to content himself with a subordinate post as chemist at the Mint. While at the Mint he carried out important investigations on the chemistry of metals, adding considerably

Journ. of Hyg. I 
to his reputation: at last, in 1847 on a change of ministry, he was appointed to a special Chair of Pathological Chemistry. In 1850 he presented to the Bavarian Academy a remarkable paper, in which he drew attention to some of the main facts which form the basis of what is now so well known as the Periodic Law of the Elements. The importance of this paper was not recognised by the Academy, which, to Pettenkofer's great disappointment, declined to give him the means of carrying on the investigation. Pettenkofer thus shared the fate of Newlands in this country. Nearly fifty years later (in 1899) the German Chemical Society conferred on him the Liebig medal in tardy recognition of the merits of his work of 1850.

From about 1850 onwards Pettenkofer directed his attention more and more to investigations in Hygiene, and in 1853 he began to give courses of lectures devoted entirely to the subject. A Chair of Hygiene was founded for him in 186.5, and in 1878 the famous laboratory of Hygiene at Munich was built under his direction. He held the Munich Chair until 1894.

The Zeitschrift für Biologie, which was devoted partly to Physiology and partly to Hygiene, was founded by Pettenkofer, Voit, and two of their colleagues in 1865. In it appeared until 1883 nearly the whole of the important series of investigations carried out by Pettenkofer and those associated with him. In consequence of the increasing importance of the subject of Hygiene, he, in conjunction with Professors Forster and Hofmann, founded the Archiv für Hygiene, of which he continued to be one of the editors until 1895.

It is only possible here to give a very short account of Pettenkofer's scientific work in connection with Hygiene. His published papers deal mainly with three lines of investigation, relating respectively to nutrition, to certain epidemic diseases, and to vitiation of air.

In his work on nutrition and dietetics Pettenkofer was associated from the beginning with his colleague Professor Voit. The first step in their investigations was the invention by Pettenkofer of his famous respiration apparatus, which was erected with the help of a grant of $£ 1000$ from the King of Bavaria, and described in 1858. Pettenkofer's object in constructing it was to obtain complete information as to all the sources of gain and loss to the body over a given period, the man or animal experimented on being kept under perfectly normal conditions. In previous experiments on nutrition and the effects of various diets the nitrogen, but not the carbon, oxygen and hydrogen leaving and entering the body had been determined, so that there 
was then only an imperfect knowledge of the relation of diet to the oxidation of material in the body. How incomplete such knowledge was will be evident from our example. We now know, thanks to the use of the respiration apparatus, that during starvation, although the excretion of nitrogen, which is an index of proteid oxidation, may fall to a fraction of its normal value, yet the total amount of material oxidised remains about the same; for although the oxidation of proteid is diminished, this diminution is compensated for by increased oxidation of fat. Proteid, carbohydrate and fat are in fact capable, within certain limits, of replacing one another; and the proportion of one of these substances which replaces another depends, as shown by Rubner, on the relative energy-values of the two substances. When, for instance, fat is substituted for proteid, the amount of energy liberated in the body by the oxidation of the proteid replaced is equivalent to that liberated by the fat substituted for it. Observations merely on proteid metabolism, as indicated by the nitrogen of the urine, give, therefore, only very partial, and by itself misleading, information as to the consumption of material in the body.

With characteristic insight Pettenkofer perceived the necessity of observing over considerable periods not only the excretion of nitrogen and other constituents of the urine and faeces, but also the output of carbonic acid and intake of oxygen. The respiration apparatus, which was further improved by Voit, furnished the means of obtaining the latter data, and thus rendered possible the long and very important series of investigations carried out at Munich by Voit, Pettenkofer and their pupils. Through these investigations a far more complete insight has been obtained into the part played in nutrition by the different constituents of food, the effects of variations in the quantity of food taken, and many other important questions. It may be said with strict truth that the experiments of the Munich school form the chief basis of our present knowledge of dietetics.

The second line of investigation pursued by Pettenkofer relates to the causes of epidemic disease, in particular cholera and typhoid. About the time when he settled in Munich both cholera and typhoid were formidable sources of danger, and naturally attracted his special attention. In Munich the annual death-rate from typhoid alone was sometimes as high as 3 per 1000, or about 15 times the present rate in England. Pettenkofer set himself to investigate the causes of the prevalence of these two diseases; and he continued his investigations over forty years. The conclusion to which he was led, and which he 
continued to the end to urge with undiminished vigour and ability, was that although cholera and typhoid are due to specific organisms, introduced from without, these diseases are nevertheless not spread as epidemics by immediate infection from person to person, as in the case of small-pox and many other infectious diseases. For their epidemic spread certain local conditions are necessary; and apart from the presence of these conditions the mere introduction of the organism causing typhoid or cholera is of little importance. In support of this view he pointed both to experience of the slight danger from direct contact with patients, and to the fact that many places remain immune to cholera or typhoid although the germs of the disease are constantly being introduced by infected persons coming from elsewhere. As the result of long investigations at Munich and elsewhere, he inferred that the chief local condition for the spread of cholera and typhoid is a soil charged with organic impurities and in a certain condition of dryness and porosity. With regard to typhoid in particular he showed that its prevalence in Munich coincided with a fall in the level of the ground-water, which implies drying of the soil. He further maintained that such measures as quarantine, disinfection, and isolation are ineffective in practice against cholera and typhoid, whereas by keeping the soil pure by an effective system of sewers, with sufficient water-supply to carry away all impurities, epidemics of cholera and typhoid may be effectually prevented. He vigorously öpposed the theory that typhoid and cholera epidemics are caused by the drinking of water contaminated directly by the excreta of persons suffering from these diseases; and both he and his pupil Emmerich performed on themselves the daring experiment of swallowing a fresh culture of the comma bacillus, after neutralising with soda the contents of the stomach. In each case the result was a watery diarrhoea, the discharge being an almost pure cultivation of the comma bacillus. The accompanying symptoms were, however, very slight as compared with typical cholera, and Pettenkofer considered, whether rightly or wrongly, that the experiment confirmed his views.

On going through the great mass of evidence contained in Pettenkofer's writings, and particularly the facts with regard to Munich, where typhoid, in consequence apparently of the purification of the soil by a proper drainage system, has now almost disappeared, it is difficult to come to any other conclusion than that his contentions embody a very important element of truth. On the other hand the proof of the spread of cholera and typhoid in particular epidemics by water is now so strong 
that few will follow him in denying that this means of spread is of common occurrence.

Pettenkofer's third main line of investigation was connected with the principles of ventilation, and the manner in which the air of inhabited buildings becomes vitiated. His earliest published work on this subject contains a description of his well-known method for the determination of $\mathrm{CO}_{2}$ in air. A very similar method had, unknown to him, been used by Dalton and Watson in England; but it was Pettenkofer who gave the method its present form, and at the same time showed how it could be made use of for measuring the degree of vitiation of the air of rooms. With the help of this method he and his pupils investigated the proportion of $\mathrm{CO}_{2}$ which corresponds to a reasonable standard of purity in the air of inhabited rooms, the rate at which air passes through the walls of a closed room under various conditions, the composition of ground air and its penetration into houses, the vitiation of air by lights, the efficiency of various systems of ventilation, and other important questions. A further series of experiments carried out in his laboratory related to carbonic oxide poisoning from the passage of lighting gas through the soil into houses from broken gas mains, the deodorisation of this gas in its passage through the soil, and the effects on men and animals of small proportions of $\mathrm{CO}$ in the air breathed.

It is not merely for the importance of the actual scientific work which he accomplished that Pettenkofer will be remembered: for it is chiefly through his influence that Hygiene has secured recognition as a definite branch of applied science, based solely on careful and accurate observation and experiment. The great importance to the community of practical measures relating to Public Health has for long been recognised and acted upon, particularly by statesmen and leaders of medical opinion in England. Pettenkofer not only helped to secure this recognition in Germany, but insisted on the equal importance of obtaining a sound scientific basis for all practical measures carried out by the community in the interests of Public Health. Largely in consequence of his efforts Germany has now chairs of Hygiene with efficiently equipped laboratories in all but one of her twenty universities, besides the celebrated Kaiserliche Gesundheitsamt at Berlin, of which the directorship was at first offered to him. It is only necessary to consider the work already accomplished in connection with these laboratories in order to see how great has been the benefit to humanity which their establishment has conferred. England, which was formerly far ahead in matters of Public Health, has unfortunately 
lagged behind in recent years. The scanty and inadequate provision made in this country for the advance of that definite knowledge which is the only sound basis for administrative work in Hygiene contrasts very unfavourably with what now exists in Germany.

Much of Pettenkofer's influence was due to his genial personality, and to the power, which he possessed in an extraordinary degree, of clearly and vigorously expressing his thought, and carrying with him the interest of his readers. Of all his numerous papers not one is dull or obscure.

He resigned his chair in 1894, and the editorship of the Archiv für Hygiene shortly afterwards. He felt himself no longer physically fit for active work, although, to judge from his latest writings, he was mentally as vigorous as ever. A pathetic interest attaches to what he wrote at the beginning of his description of the experiment-one of the last he performed-in which he swallowed a cultivation of the cholera-bacillus.

" On the 7th of October, 1892, in the presence of witnesses, I took this cholera-drink, which tasted like the purest water. Some of my friends were concerned for me, and asked that if I were determined that the experiment should be made they might be allowed to sacrifice themselves in place of their old teacher; but $I$ wished to act according to the old maxim : fiat experimentum in corpore vili. I have the right to consider myself as a corpus vile. I am 74 years old, I have suffered for years from glycosuria, have not a single tooth left, do not even use my artificial teeth in eating, but only when $I$ have to speak long and clearly, and I feel also other burdens of old age. Even if I were mistaken and the experiment endangered my life I should look death calmly in the face, for it would be no thoughtless and cowardly suicide: I should die in the service of Science as a soldier on the field of battle. Health and life, as I have often said, are very high earthly gifts, but not the highest for man. The man who wills to stand higher than an animal must be ready to sacrifice even life and health for a higher ideal good."

On retiring from active work he went to live at his house in the country, and those who visited him there found his welcome as genial, and his interests as keen as ever, although he evidently felt deeply his separation from the work he loved so well. The news of his sudden end while in a fit of deep depression came as a shock to the many, in all civilised lands, who honoured him not more for the greatness of his work than for the greatness of his character.

J. S. H. 